\title{
COMUNIDAD, INMUNIDAD, ZOOPOLIS. REPENSANDO LA COMUNIDAD POLÍTICA MÁS ALLÁ DE LO HUMANO*
}

\author{
Diego Rossello \\ Departamento de Filosofía, Universidad Adolfo Ibáñez \\ diego.rossello@uai.cl \\ Matías Saidel \\ UCSF-CONICET / UNER \\ matiaslsaidel@gmail.com
}

\begin{abstract}
RESUMEN / ABSTRACT
El presente trabajo discute el concepto de comunidad en la obra del teórico italiano Roberto Esposito y su relación con literatura reciente en la teoría de los derechos de los animales. Se argumenta que la communitas teorizada por Esposito constituye un aporte a la configuración de una comunidad más allá de lo humano, de un modo que al mismo tiempo enriquece y problematiza la idea de comunidad presupuesta, pero no teorizada explícitamente, por Sue Donaldson y Will Kymlicka en la noción de zoopolis.

Palabras Clave: comunidad, inmunidad, Zoopolis, animales, política.

\section{COMMUNity, IMMUNity, Zoopolis: Rethinking the Political BEYOND THE HuMaN}

The paper discusses the concept of community in the work of Italian political theorist Roberto Esposito. The relationship between Esposito's idea of communitas and recent literature in animal rights theory is explored. It is argued that the communitas theorized by Esposito contributes to rethinking the political beyond the human, in ways that complement, but also challenge, the idea of political community presupposed in, but not explicitly theorized by, Sue Donaldson and Will Kymlicka's notion of zoopolis.
\end{abstract}

KEYWORDS: Community, Immunity, Zoopolis, Animals, Politics.

\section{Introducción}

El presente trabajo discute el concepto de comunidad en la obra del teórico italiano Roberto Esposito y su relación con literatura reciente en la teoría de los derechos de los animales. Se propone que, por un lado, Esposito contribuye a entender los vínculos que dan sustento la comunidad política a partir de su crítica al rol que

El presente artículo tiene lugar al interior de un proyecto Puente-PAI UAI 2021. 
cumplen en ellos la persona y lo personal. Por otro lado, se sugiere que el denominado giro político en la teoría de los derechos de los animales apuesta a reconfigurar la comunidad política más allá de la frontera de lo personal y lo humano, concibiendo a dicha comunidad como una zoopolis. En este marco se argumenta que la communitas teorizada por Esposito constituye un aporte a la configuración de una comunidad más allá de lo humano, de un modo que al mismo tiempo enriquece y problematiza la idea de comunidad presupuesta, pero no teorizada explícitamente, por Sue Donaldson y Will Kymlicka (D\&K) en la noción de zoopolis.

Como es sabido, la sabiduría académica convencional en la filosofía política y la teoría social opone el concepto de comunidad al de sociedad. Esta sabiduría opone también el llamado comunitarismo al liberalismo y asocia al primero con proyectos políticos nacionalistas, organicistas e incluso totalitarios. Más allá de este saber sedimentado entonces, el trabajo de Esposito propone una indagación del tipo de vínculo o relación (munus) que podría dar forma a lo común y que permitiría repensar las posibilidades de un pensamiento de la comunidad. Dicho vínculo o relación no excluye, según Esposito, la posibilidad de construir formas de lo común que sean al mismo tiempo impersonales, singulares y plurales, en lugar de constituir macro sujetos sociales orgánicos, autotransparentes y cerrados sobre sí mismos. Como se verá a continuación, desarrollos recientes de la teoría de los derechos de los animales coinciden en explorar nuevos tipos de vínculos ciudadanos en una comunidad política plural, pensada más allá de la persona humana y reconfigurada como una zoopolis. En dicha comunidad política más que humana, D\&K sugieren que los animales domésticos deben ser considerados como ciudadanos que poseen un tipo especial de agencia y que los animales salvajes deben ser concebidos como soberanos de y en los territorios que ocupan.

En efecto, el texto Zoopolis: A Political Theory of Animal Rights (2011) constituye el esfuerzo más sostenido que desde la filosofía política liberal se hecho en años recientes para incorporar a los animales no humanos al ámbito no solo de los derechos, sino también de la ciudadanía. Sin embargo, y de manera especialmente relevante para nuestro argumento, D\&K consideran que los animales no-humanos, a diferencia de las plantas o los micro-organismos, deben ser considerados dentro de la categoría de personas y es por ello que tenemos hacia ellos obligaciones de justicia. En los términos de los/as autores/as canadienses:

La cuestión del yo o la personalidad define a un grupo de seres a los que se les debe justicia y derechos inviolables. (...) Solamente un ser que posee experiencia subjetiva puede tener intereses, o se pueden tener con él obligaciones directas de justicia que protejan esos intereses. Una roca no es una persona. Tampoco lo es un ecosistema, una orquídea, o una cepa de bacteria. Estas son cosas. Pueden ser dañadas pero no pueden ser sujetos de injusticia. La justicia es debida a sujetos que experimentan el mundo, no a cosas (las cursivas son nuestras) (2011, p. 36).

Resulta interesante notar que uno de los proyectos teóricos más hospitalarios con los animales no-humanos presentado en los últimos años resalta la necesidad de incluir a dichos animales en la categoría de persona como paso conceptual ineludible para realizar dicha inclusión. No obstante, resulta pertinente para nuestros propósitos resaltar 
que D\&K movilizan un vocabulario teórico-político basado en la idea de comunidad para dar cuenta de la noción de zoopolis por ellos defendida. En este sentido, D\&K admiten tempranamente en su texto que la idea de zoopolis está inspirada por una idea de comunidad con visión integradora, que abarca tanto a los seres humanos como a los animales no-humanos. En sus términos:

Jennifer Wolch acuñó el término "Zoopolis" (1998) para describir una ética ambientalista urbana que abraza una visión integrada de la comunidad humana y animal. Su proyecto nos ha inspirado y tomamos prestado el término con gratitud, aunque nuestro foco sea en una manera más amplia de entender la "polis" como comunidad política, y como un conjunto de maneras más abarcadoras de relacionarse con esa comunidad (las cursivas son nuestras) (2011, p. vi).

La pregunta que surge entonces es hasta qué punto D\&K pueden ser coherentes consigo mismos al plantear, al mismo tiempo, la necesidad de elevar a los animales no humanos hacia el estatus de persona y reivindicar lazos comunitarios más allá de lo humano. ¿No sería acaso el movimiento hacia lo personal una forma de horadar los vínculos comunitarios que, de tener Esposito razón, deben ser impersonales? ¿No afecta el concepto de persona la posibilidad de pensar nuevos vínculos comunes más allá de lo propio, lo personal y lo humano? En lo que sigue intentaremos dar respuesta a estos interrogantes.

El presente artículo procede del siguiente modo. La primera sección introduce el problema a ser discutido: la tensión entre comunidad, persona y animalidad en las teorías de Esposito y D\&K. La segunda sección presenta, a modo de prolegómeno a la discusión, una breve genealogía del concepto de comunidad en la teoría social y política, desde fines del siglo XIX hasta nuestros días. La tercera sección desarrolla una discusión extensa del aporte que hace Esposito a una nueva manera de concebir el vínculo que conforma lo común y que puede dar lugar a nuevas formas de pensar la communitas. La sección cuatro construye un diálogo crítico entre Esposito y D\&K en el cual el primero aporta conceptos como communitas y lo impersonal y los segundos un bosquejo de una comunidad política cuya ciudadanía se extiende más allá del ser humano. La última sección concluye planteando agendas de investigación que surgen a partir de pensar nuevas formas de lo común más allá de lo humano y lo personal.

\section{Notas sobre el concepto de comunidad}

Si bien el concepto de comunidad nunca desapareció totalmente del debate académico, puede afirmarse que fue desplazado del centro de atención de la teoría política y social durante la mayor parte del siglo XX. Inspirada en el trabajo de Ferdinand Tönnies, la teoría social de fines del siglo XIX opuso la noción de Gemeinschaft (comunidad) a la de Gesellschaft (sociedad) (Tönnies [1887] 2001). La primera es entendida por Tönnies como un tipo de asociación en la que priman relaciones sociales tradicionales y cara a cara, basadas en lazos familiares y telúricos consuetudinarios, mientras que la segunda corresponde a la voluntad racional característica de la modernidad en las sociedades cosmopolitas, con grandes organizaciones industriales y burocráticas, donde 
la asociación entre individuos se basa en el interés ${ }^{1}$. Sin embargo, el abuso del concepto de comunidad, especialmente con el uso racialmente connotado de Volksgemeinschaft durante el nazismo, lo volvió sospechoso para los pensadores europeos. En ese marco, el concepto de comunidad es reintroducido al debate académico de la teoría política recién en los años 80 del siglo pasado. En ese momento, pensadores como Alasdair MacIntyre, Charles Taylor y Michael Sandel, entre otros, plantearon una serie de objeciones al liberalismo de Robert Nozick y John Rawls y dieron forma a lo que se dio en llamar el debate entre liberales y comunitaristas (MacIntyre 1984; Taylor 1989; Sandel 1982).

De este modo, los teóricos denominados comunitaristas reintrodujeron ideas de inspiración aristotélica y hegeliana para hacer frente a un liberalismo percibido como abstracto, racionalista, universalista y atomista. A partir de esas ideas reivindicaron la existencia de tradiciones lingüísticas, axiológicas, culturales y de discurso concretas, así como de vínculos políticos intensos entre las personas, como la amistad cívica y el patriotismo. Aunque al parecer este grupo de pensadores nunca se autodescribió como comunitarista, pensadores posteriores como Amitai Etzioni o William Galston sí lo hicieron (Etzioni 1995; Galston 1993). Esta segunda generación de comunitaristas argumentó que la disolución de la familia, el desapego individualista y la carencia de valores comunes, así como la creciente distancia e impersonalidad del Estado burocrático generan, tomados en conjunto, un déficit preocupante de integración social (Bell 2016).

Paralelamente, desde principios de este siglo, un conjunto de pensadores franceses e italianos ha venido repensando la noción de comunidad desde otra perspectiva. El texto pionero e inspirador de este grupo de teóricos ha sido La comunidad inoperante del filósofo francés Jean-Luc Nancy, publicado en 1983 (Nancy [1983] 1991). En dicho texto, Nancy analiza y critica lo que denomina la nostalgia de la comunidad perdida, entendida como unión política arcaica y original que podría ser recuperada en el futuro. Nancy advierte acerca de este deseo inmoderado de unión al que denomina inmanentismo y al que describe como un anhelo de identidad perfecta y cerrada sobre sí misma. Para Nancy, manifestaciones concretas de ese anhelo pueden ser, y han sido, el nacionalismo, la exaltación de la pureza étnica o racial e, incluso, las versiones del comunismo desarrolladas por los socialismos reales. Todas estas experiencias, sugiere Nancy, expresan la nostalgia de una comunidad perfecta y sin fisuras cuyo mayor riesgo es devenir en totalitarismo.

En ese sentido, Nancy va a considerar que la Gesellschaft no vino a destruir una Gemeinschaft anterior, sino que la comunidad es nuestro problema desde y a partir de la sociedad y que, como lugar de reconciliación, la comunidad es un mito proyectado retroactivamente desde la sociedad (1999, p. 34). Estas preocupaciones serán compartidas, complementadas y desarrolladas por Esposito desde una perspectiva sobre la comunidad que, como veremos a continuación, es a la vez ontológica y deconstructiva.

De todos modos, Esposito sostiene que hay en Tönnies un "manierismo postromántico", donde lo que está en juego es la apropiación originaria de la propia esencia, que comienza por la apropiación del territorio (2003: 24, n8). 


\section{Roberto Esposito: pensador de la comunidad}

Si bien el texto pionero de Nancy suscitó una inmediata respuesta tanto de Maurice Blanchot (1983) como de Giorgio Agamben (1990; 2000), el pensador italiano Roberto Esposito es, sin embargo, quien ha llevado a cabo un proyecto sistemático y de largo aliento con el objetivo de repensar la noción de comunidad de manera radical $^{2}$. En especial en la trilogía Communitas, Immunitas y Bios, pero también en textos anteriores, como Categorías de lo impolítico, y posteriores como Comunidad, Inmunidad y Biopolítica, Tercera Persona, Pensamiento viviente, Dos y Política y negación, Esposito ofrece una genealogía alternativa de la idea de comunidad que le permite, al mismo tiempo, deconstruir el concepto heredado de Gemeinschaft y proponer una ontología de lo común que tiene en cuenta la dimensión conflictiva de toda relación política (Esposito 2003; 2005; 2006; 2009a; 2009b).

En efecto, la deconstrucción del concepto tradicional de comunidad que propone Esposito aparece con claridad en la última sección de su primer gran libro, Categorías de lo impolítico. Allí, Esposito recupera las lecturas que Blanchot y Nancy hacen de la comunidad en el pensamiento de Georges Bataille en términos de imposibilidad y desobramiento. De hecho, hemos sugerido que si bien la tonalidad impolítica atraviesa todo el pensamiento espositeano sobre lo común y se proyecta hacia sus trabajos sobre la biopolítica, lo impersonal y la negación, también es notable el cambio de enfoque que va experimentando su trabajo desde el momento específicamente impolítico hacia el intento de elaboración de una ontológica afirmativa.

Para Esposito, lo impolítico es una perspectiva, un modo de mirar a lo político desde sus confines, sustrayéndose a toda forma de teología política y, a la vez, a toda forma de despolitización. Lo impolítico se caracteriza por una vocación de llevar la deconstrucción que Heidegger realizara de la metafísica y Nietzsche de la moral a unas categorías políticas que si bien habían sido historizadas por la historia conceptual (Begriffsgeschichte), seguían siendo abordadas de manera frontal y permanecían por ende inmunes a la ola deconstructiva que se abatía sobre otros campos de reflexión-como por ejemplo la literatura. En ese marco, Esposito sostendrá que la filosofía política desde Platón en adelante ha hecho impensable la política porque busca desterrar aquello que constituye la esencia de la política, es decir, el conflicto por el poder. En ese sentido, cuando encuentra el conflicto y lo representa, en ese mismo gesto la filosofía política busca subsumirlo al orden. Para Esposito, tanto la teoría de la representación sustancial de la teología política católica, como la relación inmanente representante-representado, propia de la teología política hobbesiana, generan en última instancia una deriva hacia la despolitización (Esposito 2009a, p. 12).

2 Si en cambio nos referimos a lo común, caben destacar los enormes aportes realizados por Michael Hardt y Antonio Negri $(2005,2011,2019)$ como por Pierre Dardot y Christian Laval (2015), quienes intentan rebatir la lectura ontológica de lo común propuesta por Nancy y Esposito. 
Lo importante para nuestro tema es que después de haber deconstruido la conjunción entre el bien y el poder, propia de la teología política católica, y discutido distintas perspectivas desencantadas de la política y de la condición humana en el siglo XX, que además producen una deconstrucción del subjectum metafísico y político, Esposito concluye su libro con un comentario sobre la comunidad de la muerte en Bataille. En ese comentario Esposito declara que la cuestión de la comunidad marca un umbral en que lo impolítico se reencuentra con una cierta exterioridad. Pero esa comunidad a la que alude Esposito nada tiene que ver con la de los estados y los pueblos, sino que será una comunidad de ausencia, negativa, imposible, sustraída a cualquier deriva míticooperativa y donde la subjetividad estalla en la experiencia compartida del éxtasis. La figura empleada es la de una comunidad, como ya se dijo, de la muerte, inspirada en la tragedia de Numancia relatada por Cervantes, donde los numantinos asediados se dan muerte recíprocamente para no caer en manos del ejército de Escipión. Esta obra estaba siendo representada en París cuando Bataille se embarca en la experiencia de la revista Acéphale. Dicha experiencia incluyó el intento de realizar un sacrificio humano que fracasó, porque si bien aparecieron voluntarios para ser sacrificados no ocurrió lo mismo para cubrir el rol del verdugo. Lo que la experiencia de Numancia/Acéphale mostraría es que, por un lado, como sostenía Blanchot, la muerte que concierne al sujeto no es la propia sino la del otro, y que esa experiencia, la más propia, es a la vez la más impropia, pues es imposible morir con el otro y por el otro. Por otra parte, se evidenciaba que la decapitación soberana, la destrucción de la monocefalia cesarista y la posibilidad ya no de una democracia policéfala sino de una auténtica acefalía, de una comunidad sin dominación y sin sujeto, es a la vez imposible y necesaria.

En ese sentido, vemos que la comunidad aparece ya como una figura extrema de lo impolítico, que cuestiona una representación funcional al orden y una soberanía que se basa en la disolución, típica de la filosofía política hobbesiana, de cualquier tipo de lazo comunitario que no pase por aquel de protección y obediencia. La comunidad estará relacionada no solo con la finitud que lo impolítico subraya sino también con una exposición recíproca a la alteridad que implica siempre la posibilidad del con-flicto, del con-tacto, del contagio. La comunidad es impolítica porque a la reductio ad unum de la soberanía moderna, que busca eliminar el conflicto del orden civil, le opone la pluralidad irrepresentable de la política y de la existencia compartida. La comunidad de la muerte en Bataille es precisamente un modo posible de representarnos esa irrepresentabilidad, ya que lo que une a los sujetos no es una sustancia, una identidad, ni un interés, sino una imposibilidad operativa.

Dicha imposibilidad se verá confirmada en la concepción espositeana de la communitas, en un paso de la analítica de la finitud a una ontología de lo común y de la exposición que contrasta con todas las filosofías de la comunidad del siglo XX (organicismo, comunitarismo, éticas de la comunicación) que parten de la primacía del sujeto como completa presencia ante sí y plena posesión de la propia sustancia (Esposito 2009 b, p.14) y que por ende entienden a la comunidad como una cualidad que se añade a los sujetos, "como aquella sustancia que conecta a determinados sujetos entre sí en el reparto de una identidad común” (2012, p. 101). De esa manera, la comunidad era 
ligada conceptualmente a lo propio, donde los sujetos "tienen en común su carácter de propio y son propietarios de aquello que es su común” (Esposito 2009b, p. 15).

En ese sentido, al igual que Nancy, Esposito comienza por una deconstrucción de la noción operativa y plena de comunidad, en diálogo con Bataille, para luego pasar a elaborar una ontología de lo común de fuerte inspiración heideggeriana. Por un lado, Esposito rescata la investigación de Nancy sobre el estar-con (Mitsein) en Heidegger, porque abre paso a una interrogación de la co-existencia del Dasein (Mitdasein) entendida como aquello que vincula al Dasein con otros. Según Esposito, Nancy ha tenido el mérito de haber sugerido que la comunidad no pone en relación a determinados sujetos, sino que la comunidad sería el ser mismo de la relación: "la comunidad no es un ser común, sino el modo de ser en común de una existencia sin esencia" (Esposito 2009a, p. 16). En términos de Esposito, de lo que se trata es de sacar "la cuestión de la comunidad del horizonte de la subjetividad" (Esposito 2012, p. 102).

Nancy logra pensar este vínculo más allá de la oposición entre la desvinculación radical, que caracterizaría al sujeto atomista del liberalismo, y la vinculación fuerte que le opone el comunitarismo ya comentado. Sin embargo, Esposito considera que al centrarse exclusivamente en el con/cum de la communitas, la perspectiva de Nancy corre el riesgo de quedar atrapada en el horizonte de la subjetividad y de no poder aportar a una reflexión específicamente política sobre lo común. En ese marco, y en contraste con la postura de Nancy, Esposito pondrá el foco en la noción de munus. Según Esposito, esta diferencia lexical tendrá importantes consecuencias filosóficas ya que, como veremos, mientras desde una ontología del con parece imposible pensar la política, la noción de munus habilitará un pensamiento de lo común que al mismo tiempo que reconoce el carácter constitutivo del conflicto permite, en la oposición de communitas-immunitas, vincularse con la biopolítica y por ende con una ontología del presente de inspiración foucaulteana. ¿Pero qué significa el munus y por qué es importante para re-pensar la comunidad?

Para explicarlo, Esposito realiza una reconstrucción filológica y genealógica de la noción de munus. Siguiendo a Marcel Mauss y Emile Benveniste, existe una polisemia en el término munus, ya que se vincula directamente con onus, officium y donum, es decir, remite a un deber, a una carga pública y al don. Dicha polisemia es asumida por Esposito al entender al munus como un don que se da de manera obligatoria y que por ende no pertenece a nadie de manera estable. El munus es el don que no se posee sino que "se da porque se debe dar y no se puede no dar" (énfasis en el original) (2003, p. 28). En este sentido, para Esposito el munus que com-parte la communitas "no es una propiedad o pertenencia. No es una posesión, sino, por el contrario, una deuda, una prenda, un don-a-dar (...) Un deber une a los sujetos de la comunidad -en el sentido de 'te debo algo', pero no 'me debes algo'-, que hace que no sean enteramente dueños de sí mismos" (2003, p. 30). En consecuencia, para Esposito no existe un elemento positivo que al ser compartido por sus miembros pueda constituir el fundamento de la comunidad sino que, por el contrario, esta última implica una "despropiación que inviste y descentra al sujeto propietario, y lo fuerza a salir de sí mismo. A alterarse" (2003, p. 31). La comunidad es com-partición (partage) de un don obligatorio, un conjunto de personas unidas no por una propiedad sino por una falta, no por un más 
sino por un menos (2003, p. 29), por una ausencia. Esta ausencia es el propio munus que nos expropia y expone al contagio con el otro (Saidel 2012, p. 19). En palabras de Esposito:

En la comunidad, los sujetos no hallan un principio de identificación, ni tampoco un recinto aséptico en cuyo interior se establezca una comunicación transparente o cuando menos el contenido a comunicar. No encuentran sino ese vacío, esa distancia, ese extrañamiento que los hace ausentes de sí mismos (...) No sujetos. O sujetos de su propia ausencia, de la ausencia de propio (2003, p. 31).

En otro texto agrega:

Si nos atenemos a su significado originario, la comunidad no es aquello que protege al sujeto clausurándolo en los confines de la pertenencia colectiva, sino más bien aquello que lo proyecta hacia fuera de sí mismo, de forma que lo expone al contacto, e incluso al contagio, con el otro (2009, p. 16).

Como vemos, la comunidad aparece en Esposito como constitutiva, en el sentido de que el Mitsein y el Mitdasein no son meras determinaciones del Dasein sino que lo constituyen como tal y en ese sentido es que no puedo decir ego sum sin decir implícitamente ego cum. Al mismo tiempo, la comunidad es aquello que impide al sujeto ya constituido permanecer cerrado sobre sí mismo, puesto que el munus lo lacera y lo expone al contagio con el otro. Por eso mismo, esta ontología de la exposición se aleja tanto de las éticas centradas en la primacía de la alteridad (Lévinas, Blanchot) como de las filosofías de la intersubjetividad (Habermas).

A partir de esta manera de abordar el vínculo de la communitas, Esposito disloca, por decirlo así, el campo semántico que la teoría social había establecido para ese concepto. Así, para Esposito la communitas no debe ser pensada en oposición a la sociedad sino que su opuesto simétrico es la immunitas o inmunidad. En contra de la sabiduría académica convencional Esposito sugiere que si la communitas remite hacia lo impersonal e impropio, y por ello nos empuja más allá de nosotros mismos, la immunitas opera delimitando y fortaleciendo las fronteras de lo personal y propio. En palabras de Esposito:

...si la communitas es aquello que liga a sus miembros en una voluntad de donación hacia el otro, la immunitas es, por el contrario, aquello que exonera de tal obligación o alivia de semejante carga. Así como 1a communitas remite a algo general y abierto, la immunitas reconduce a la particularidad de una situación definida precisamente como algo que se sustrae a la condición común $(2009$, p. 17).

Por lo tanto, si para Esposito la communitas implica un vínculo construido a partir de un don que se debe al otro, pero que no tiene sentido conceptualizar como propio o apropiado, la inmunidad nos dispensa de ese don y nos restituye a la supuesta seguridad de las fronteras que, por un lado, delimitan lo propio y, por otro, expulsan y nos separan de lo ajeno/otro. En ese marco, Esposito presenta distintos escenarios en los que se despliega esta lógica inmunitaria. 
Uno de ellos es la idea de inmunidad diplomática y parlamentaria, que exceptúa a su beneficiario de ciertos aspectos de la ley común y conocida $(2012$, p. 2). Otro de los escenarios es la idea de que el derecho es, en sí mismo, parte de la lógica inmunitaria, porque cada vez que lo impropio e impersonal a los que remite la communitas pugna por hacerse presente, el derecho "vuelve a ubicar en el centro de la escena a la persona como único titular de derechos" (2005, p. 38). En este sentido, Esposito analiza la función inmunitaria del derecho respecto a la comunidad. El derecho salvaguarda la vida de la comunidad de la posibilidad de un conflicto mortal en forma negativa, oblicua, garantizando su supervivencia. Pero el peligro mayor del que protege el derecho es, para el autor, el cum de la communitas, que quiebra los límites identitarios de los individuos y los expone a la alteración y a un potencial conflicto por parte de otros. Uniendo a sus miembros en un vínculo de reciprocidad, confunde sus límites, lo que es propio con lo que es de todos. El derecho reacciona reconstituyendo los límites amenazados por el poder conectivo del munus. Para mantener a la comunidad con vida, el derecho la arranca de su significado más intenso. El derecho constituye la comunidad destituyéndola. Esforzándose por hacerla más propia, la hace necesariamente menos común (2005, p. 37), y para ello se vale de la violencia si es necesario. En efecto, el derecho no se opone a la violencia en general sino solo a aquella que le es exterior. Por ello, siguiendo a Walter Benjamin, Esposito caracterizará al derecho como "una violencia a la violencia por el control de la violencia" (2005, p. 46).

El otro vector principal de la lógica inmunitaria es el de la biología y la medicina. Allí, se entiende que el sistema inmunológico de un organismo vivo establece una barrera entre lo propio y lo extraño, defendiéndolo de amenazas externas como virus, bacterias, etc. De este modo, la inmunidad sería el producto de un sistema cuya lógica reside en poder distinguir, con la mayor claridad posible, lo propio de lo otro-extraño, y de poder actuar en consecuencia para eliminar la amenaza que lo extraño supone para lo propio. Esposito modula las implicancias de este modelo inmunitario no solo en relación con la lógica del contagio y la enfermedad, sino también en escenarios en los que la distinción entre propio y extraño se desdibuja, como en el síndrome de inmunodeficiencia adquirida y las enfermedades autoinmunes. Además, Esposito reflexiona desde esta lógica sobre la inmigración sugiriendo que el cuerpo político defiende su identidad inmunizándose frente a la incursión no deseada de un agente extraño o extranjero (2009, p. 112).

Como vemos, los más diversos lenguajes modernos, del derecho a la medicina, de la antropología a la teología, de la teoría bélica a la inmunología celular, están atravesados por la lógica inmunitaria que consiste en una protección de la vida mediante aquello que la niega ${ }^{3}$. En ese marco, el paradigma inmunitario permite comprender el devenir

3 De esta cuestión de la inmunidad se han ocupado entre otros Derrida, Haraway y Sloterdijk. Es llamativo sin embargo que Byung-Chul Han decrete con su estilo tajante el fin de la violencia inmunitaria a favor de una violencia neuronal consistente en la autoagresión y autoexplotación en un momento político en el que asistimos a la proliferación de muros y medidas anti-inmigratorias. 
biopolítico de la modernidad y repensar la comunidad en ese cruce entre política y vida. De hecho, la especificidad del aporte espositeano para comprender la biopolítica y resolver lo que entiende como paradojas irresueltas del abordaje foucaulteano pasan por la explicación en términos de inmunización.

Para Esposito, Foucault no deja en claro ni el sentido último de la biopolítica (si es una política de la vida o sobre la vida), ni su relación con la modernidad y la soberanía, puesto que parece conjugar vida y política de manera extrínseca. El paradigma inmunitario sería más dúctil al conectar vida y política de manera intrínseca, estando ambas siempre atravesadas por la historia. En ese sentido, señalará que la propia soberanía es en la modernidad un dispositivo inmunitario-biopolítico desde Hobbes en adelante, ya que tiene por misión la protección de la vida mediante una des-socialización que niega su potencia expansiva. Es decir que, para producir la conservatio vitae, el Estado moderno debe negar la comunidad originaria atravesada por el conflicto y el deseo mimético entre cuerpos iguales en potencia y recíprocamente expuestos. Dicha deriva inmunitaria se intensifica con el descubrimiento de la inmunidad adquirida, que hace que las dosis de inmunización dependan de una decisión estratégica y, a la vez, determina, junto a los saberes de fines del XIX, como la antropología, la criminología, la filología, etc., una progresiva caída de las mediaciones entre vida y política que dan lugar a una biologización de la política y a una politización de la medicina.

Dicho proceso encontraría su culmen en el nazismo, momento en el cual el sistema inmunitario se vuelve tan agresivo que termina por atacar al propio cuerpo que busca defender, como en las enfermedades autoinmunes. En ese sentido, si para Foucault el racismo era lo que permitía explicar la paradoja de que un poder destinado a proteger la vida haya producido los mayores genocidios, para Esposito esto se debe a la radicalización de la lógica inmunitaria que permite explicar cómo la muerte puede ser un mecanismo para conservar la vida. Una vida que no puede pensarse por fuera de sus determinaciones históricas, políticas y tecnológicas. Es decir que el paradigma inmunitario permite comprender la muerte como articulación interna y mecanismo de protección de la vida, situar históricamente el funcionamiento del biopoder y, por último, evitar caer en hipótesis eufóricas (Negri) o tanatológicas (Agamben) de la biopolítica. Por eso mismo, el genocidio no es para Esposito un destino inevitable ni el paradigma de la política moderna. La protección de la vida no tiene por qué derivar en el exterminio de los otros. Communitas e immunitas son dos lógicas que operan de manera conjunta y, en todo caso, si vivimos en una época signada por una inmunización creciente, de lo que se tratará es de pensar cómo desactivar los dispositivos inmunitarios y explorar formas comunes de inmunidad, o bien, lo que también llama una biopolítica afirmativa y una política de lo impersonal.

En efecto, hacia el final de Immunitas, y frente a las concepciones de la inmunología celular que se basan en un paradigma bélico donde no hay posibilidad de compromiso con el enemigo al que se busca aniquilar, Esposito explora otra filosofía de la inmunidad, que se inspira en nociones como las de la tolerancia inmunitaria, el trasplante o la gravidez. Este último caso es especialmente significativo puesto que según el autor lo que allí acontece es que la diferencia y el conflicto entre sistemas inmunitarios es precisamente la condición de posibilidad del desarrollo de la vida del 
feto. Es decir que la protección de la vida puede darse en una exposición recíproca de las diferencias que nos constituyen. Dicha filosofía de la inmunidad mostraría de qué manera la relación con el otro, que nunca es pacífica, es lo que nos permite ser. No hay identidad sin diferencia.

Por eso mismo, la biopolítica no tiene por qué derivar necesariamente en una tanatopolítica. Esposito opone una política sobre la vida, como la que han implementado los Estados modernos, que han impuesto políticas de normalización de los cuerpos en base a una regulación de las vidas que merecen vivir y las que quedan excluidas, a una política de la vida, en la que la vida, entendida en toda su complejidad relacional y en la singularidad de cada una (une vie), sea capaz de dictar sus propias normas a la política. En ese sentido, Esposito no solo buscará invertir los dispositivos de poder implementados por el nazismo sino que buscará en la filosofía de la inmanencia un tipo de pensamiento donde la norma surja de los propios vivientes, donde lo impersonal se erija como horizonte de una política donde la persona ya no pueda someter a la cosa, al cuerpo o al animal ni reducir a otros seres humanos a dicho estatus. En este sentido, frente a los dualismos metafísicos y jurídicos que siempre esconden dentro suyo el sometimiento de un término al otro, e instituyen así alguna forma trascendente del fundamento al que lo real, o en este caso la comunidad, debe plegarse, se trata de repensar de manera inmanente la relación entre lo singular y lo común, entre cuerpo y pensamiento, más allá del dispositivo escindente de la persona.

La comunidad, entonces, tal como la vislumbra Esposito, poco tiene que ver con las comunidades que conocemos, basadas en formas identitarias de identificación y exclusión, en formas de pertenencia basadas en lo propio de una lengua, una sangre, un suelo o una posesión. Justamente la etimología planteada por Esposito evidencia la oposición constitutiva de lo común a lo propio, lo privado y lo inmune, ya que el munus que compartimos nos expropia de nuestra subjetividad, de nuestros privilegios, y nos expone a una obligación de donación para con los otros que nos obliga a alterarnos, a contaminarnos, a com-partir-nos y con-vivir. Más allá de todo cálculo, identidad y propiedad del sujeto, la comunidad lo expone a la dimensión de la existencia compartida.

Sin embargo, esta dimensión de lo común no solo ha sido ignorada por la filosofía, sino que el derecho ha dividido al mundo entre lo público y lo privado, que no son sino dos figuras simétricas y complementarias de lo inmune. Incluso lo que otrora fuera reconocido como res communes, como los bienes ambientales, y los nuevos bienes comunes culturales e intelectuales son privatizados de manera acelerada. Por ello Esposito señala que en la globalización, a la publicización de lo privado le corresponde la privatización de lo público, mientras lo común brilla por su ausencia. Es en ese terreno que se da para Esposito la batalla por una biopolítica afirmativa, protegiendo lo común respecto a lo privado, lo propio y lo inmune (Esposito 2012, p. 113).

En este sentido, más allá de la alternativa entre lo público y lo privado, entre los vínculos identitarios densos del comunitarismo y el atomismo del individualismo liberal, lo común aparece en Esposito como el espacio relacional y conflictivo, singular y plural, de una política declinada en términos impersonales, donde cada vida pueda encontrar su norma inmanente. Así, la política de la vida pasa por reconocer e instituir 
su dimensión común, hoy totalmente subsumida a los dispositivos inmunitarios. Es en este sentido que la noción de communitas puede aportar, sugerimos, a una filosofía política que va más allá de lo humano y lo personal, a sabiendas de que el ideal de la communitas resulta altamente demandante en relación con las instituciones jurídicas y políticas de las democracias representativas actualmente existentes.

\section{Comunidad, inmunidad, zoopolis}

Luego de evaluar en profundidad las tesis de Esposito sobre la comunidad, la inmunidad y lo impersonal, cabe dar un paso atrás para poder evaluar las afirmaciones del autor italiano con algo de distancia crítica en un intercambio posible con las tesis de D\&K. Desde nuestra perspectiva, su teorización del munus conduce a Esposito hacia dos frentes de confrontación que están relacionados entre sí: 1) por un lado, lo lleva a considerar al contrato, y al derecho por él originado, como formas de inmunización que construyen y delimitan lo propio y que, al hacerlo, socavan la posibilidad de la communitas; 2) por otro, lo lleva a considerar al sujeto de derechos que surge y se despliega al interior del proyecto del contrato-derecho como un producto de la lógica inmunitaria, o lo que en distintos textos Esposito denomina como el dispositivo de la persona (2009b, pp. 189ss). De este modo, lo impropio y lo impersonal aparecen como el horizonte de posibilidad de una communitas desfondada que evita construir un yo más grande, colectivo, y garantiza la posibilidad de una comunidad que podría llegar a ser, al mismo tiempo, singular, plural (Saidel 2013) y extenderse más allá de lo humano-personal.

Asimismo, consideramos prometedor el proyecto de Esposito de resaltar el carácter desfondado, o post-fundacional, de la communitas, en contraste con la subjetividad a gran escala -la comunidad como macro-sujeto- que podría adjudicarse a ciertas modulaciones de la posición comunitarista. Asimismo, aunque a primera vista la crítica de Esposito podría acercarse al cuestionamiento que hace Sandel al yo desvinculado del liberalismo, sus posiciones se distinguen en un punto fundamental: la noción de persona. En este sentido, si bien tanto Esposito como Sandel cuestionan el atomismo individualista de lo propio, el primero no plantea simplemente la posibilidad de un vínculo allí donde habría mero desvinculamiento individualista, sino que va más allá, hacia una deconstrucción de la noción misma de persona que estaría a la base de toda re-vinculación posible en clave comunitarista. Como ya se anticipara, para Esposito la persona conforma una especie de dispositivo que tiene a su cargo, por un lado, la reproducción de la distinción entre cosa y persona, a la que Esposito dedica un libro completo (2015) y, por otro, la reproducción de la dominación de la animalidad del humano en y por medio de esa noción de persona (2009a; 2009b). Es en este sentido que Esposito deriva de una interrogación de la oposición entre communitas e immunitas la necesidad de una filosofía de lo impersonal, esto es, de una filosofía que vaya más allá de la noción de sujeto humano y persona, así como del animal rationale, para replantear las condiciones de posibilidad de toda vinculación hacia lo común.

Es en este sentido que resulta productivo intentar avanzar en una agenda de investigación que articule las prevenciones de Esposito frente a lo inmunitario, lo 
propio y lo personal y la idea de comunidad post-humana presupuesta en la noción de zoopolis que presentan D\&K. Por un lado, si bien Esposito cuestiona y desestabiliza la noción de persona, a partir de identificar que esta se erige como dispositivo de control de la animalidad del ser humano, el pensador italiano no tematiza expresamente el estatus de la vida animal no humana en la communitas. Por otro lado, el texto de D\&K constituye el esfuerzo más sostenido que desde el liberalismo se ha hecho en años recientes para incorporar a los animales no humanos al ámbito no solo de los derechos, sino también de la ciudadanía. Sin embargo, y de manera especialmente relevante para nuestra discusión, D\&K consideran que los animales no-humanos, a diferencia de las plantas o los micro-organismos, deben ser considerados dentro de la categoría de personas para que tenga sentido predicar su inclusión en zoopolis. Si recordamos el argumento de D\&K citado en la introducción, para los autores solamente una persona posee experiencia subjetiva y por ello se pueden tener hacia ella deberes de justicia: "La justicia es debida a sujetos que experimentan el mundo, no a cosas" (2011: 36).

Lo paradójico en este argumento de D\&K es que al mismo tiempo que el proyecto de zoopolis intenta abrir nuevas fronteras de la ciudadanía más allá de lo humano, lo hace re-inscribiendo distinciones sedimentadas entre persona y cosa que, desde el punto de vista de Esposito, bloquean justamente toda posibilidad de ir más allá de lo propio, la persona y lo personal. Sugerimos que la noción de persona es parte central del arsenal inmunitario que nos impide con-vivir más allá de lo humano, y que obtura los efectos de despersonalización y despropiación necesarios para que el munus pueda operar sus dislocaciones hacia lo singular y plural. Así, una distinción estanca entre personas que pueden expresar un bien subjetivo y cosas que no pueden hacerlo forma parte de la lógica inmunitaria que divide aquello que debería permanecer vinculado o mancomunado en una existencia compartida y aquello que no. Puesto de otro modo, D\&K borran con el codo lo que escriben con la mano: los derechos extendidos hacia los animales no humanos dependen del mismo concepto que histórica, genealógica y analíticamente ha fundamentado su exclusión de esos derechos.

¿Cómo salir de este callejón sin salida? Resulta interesante advertir que D\&K hacen en su libro una serie de gestos en favor de la idea de comunidad. Como se explicó en la introducción, ambos aluden a que la idea de zoopolis por ellos defendida encuentra su inspiración en el concepto presentado por Wolch, que lo formula como una "visión integrada de comunidad animal y humana" (2011, p. vi). Cabe mencionar que más allá de este breve comentario sobre el trabajo de Wolch, D\&K no desarrollan en detalle qué tipo de polis, comunidad política o communitas podría ser construida a partir de la entrada de los animales no humanos a la misma. Su foco, por el contrario, está en establecer de qué manera los animales no humanos pueden ser pensados con las capacidades necesarias para la ciudadanía política democrática; las tesis que presentan son las siguientes: 1) el poseer un bien subjetivo y poder comunicarlo; 2) el poder acatar ciertas normas sociales; 3 ) el poder participar como co-autores de las leyes (2011). Más allá de la defensa convincente que D\&K hacen de estas tesis, los autores no se detienen a desarrollar de qué manera la ciudadanía animal, incluso si se la aceptase, podría reconfigurar la misma idea de comunidad política de raíz, al punto de volverla irreconocible. 
Con todo, la idea de una zoopolis resulta sugerente porque evoca una concepción aristotélica de la comunidad política basada en la idea del ser humano como zoon politikon, o animal político por naturaleza. Sin embargo, el foco principal del libro de D\&K está puesto en fundamentar, y delimitar, los modos en que puede llegar a tener sentido considerar a los animales no-humanos domésticos como ciudadanos y a los animales salvajes como soberanos, entre otras categorizaciones propuestas en su texto. Por ello, más allá del propósito de repensar la noción de ciudadanía para incluir a criaturas más allá de la frontera de la especie, algo que el comunitarismo desde Aristóteles a Sandel no podría aceptar, es poco lo que D\&K tienen para decir sobre la imagen o concepto de comunidad que podría seguirse de esta inclusión. Podría incluso forzarse el argumento y afirmar que D\&K están dispuestos a incluir a criaturas más allá de la especie siempre y cuando nuestra idea de comunidad política no se vea radicalmente desdibujada por dicha inclusión. En suma, la inclusión del animal en ciertas dosis surtiría sus efectos inmunitarios para que la comunidad no se enfermase gravemente de animalidad.

Una comentarista de D\&K ha identificado precisamente los supuestos peligros a los que se expone zoopolis al abrir la puerta a la ciudadanía animal. Para Emma Planinc (2014), D\&K no advertirían las consecuencias últimas de abrir la caja de pandora de la animalidad al momento de repensar la comunidad política. Según Planinc, la entrada de la animalidad en la polis puede afectar no solo aquello que Esposito llama el dispositivo de lo personal, sino también la idea misma de vínculo político que ha sido privilegiada desde los griegos hasta nuestros días. Sin advertirlo, D\&K nos estarían pidiendo que redefiniéramos ideas como participación democrática, libertad y justicia a la luz de la animalidad. Planinc resiste esta inclusión sobre la base de que "puede hacer más mal a la comunidad democrática que el bien que se propone al reconfigurar nuestra vida política" (2014, p. 4), ya que junto a la animalidad ingresan también a la polis la irracionalidad, los instintos y la fuerza, elementos todos que desde Platón en adelante han sido mantenidos fuera de la comunidad política justamente para garantizar la justicia, la estabilidad y el buen gobierno.

En oposición a Planinc, en el presente trabajo sugerimos que un diálogo crítico entre las posturas de Esposito y D\&K puede abrir nuevas agendas de investigación para pensar la communitas más allá de lo personal y lo humano. En el contexto en que el constitucionalismo latinoamericano hace entrar a la naturaleza en el ámbito de los derechos se vuelve imperativo evaluar si esas inclusiones de lo no-humano pueden ayudar y contribuir al ejercicio de la ciudadanía y el buen gobierno, en lugar de causar su ruina, o si bien se trata de gestos inmunitarios que al incluir lo otro al derecho, lo asimilan a lo mismo, obturando la posibilidad de exposición y afectación de lo mismo a lo otro. Con todo, la idea del munus como donación y deuda que propone Esposito alcanzaría aquí a extenderse más allá de la frontera de la especie humana, para invitarnos a pensar nuevos modos de con-vivir, de co-habitar, de com-partir y de participar en una comunidad política de nuevo tipo. 


\section{Conclusiones}

De este análisis cruzado de las posiciones de Esposito y D\&K surgen nuevos modos de pensar la comunidad política más allá de la división entre el ser humano y el animal. Si desde el pensamiento de Jacques Maritain (1961) en adelante, el proyecto de los derechos humanos de post-guerra se afincó en la centralidad de la persona humana, tanto Esposito como D\&K nos invitan a revisar los privilegios presupuestos en dicha centralidad, así como las exclusiones y violencias que el personalismo puede traer aparejado (Esposito 2009a; Rossello 2017; Kymlicka 2018). En este sentido, la idea de lo impersonal puede abrir un campo semántico y conceptual de afinidades entre la communitas de Esposito y la zoopolis de D\&K, a pesar de ciertos sesgos humanistas del primero, y de cierto apego por la idea de persona en los segundos.

De esta lectura cruzada entre los autores discutidos en este ensayo surge también la importancia que tiene cuestionar los privilegios de especie. Si las distintas olas de la teoría feminista han logrado instalar el cuestionamiento de los privilegios de género que serían característicos del patriarcado, la teoría de los derechos de los animales, y el eco-criticismo entendido en sentido amplio, han venido intentando cuestionar nuestros privilegios de especie con éxito dispar. La potencia vinculante de la donación y la idea del munus en Esposito, junto al intento sistemático y sostenido de ampliar la ciudadanía política más allá de la especie en D\&K, pueden resultar, en conjunto, en la posibilidad de una comunidad política imaginada, para parafrasear al clásico de Benedict Anderson, de un nuevo tipo (Anderson 1993; Meijer 2019). En dicha comunidad, sin embargo, para evitar que se clausure a sí misma en una totalidad envolvente y cerrada, debe poder todavía ser pensado el conflicto, la fricción y el desacuerdo. El desafío entonces, que a partir de Esposito y D\&K solo podemos entrever es cómo pensar una communitas singular y plural en la cual el agonismo pueda darse más allá de lo humano.

\section{Referencias bibliográficas}

Agamben, Giorgio (1990), La comunità che viene, Ed. Accresciuta. Torino: Bollati Boringhieri.

(2000), Il tempo che resta. Un commento alla Lettera ai Romani, $2^{\mathrm{da}}$ ed. Torino: Bollati Boringhieri.

Anderson, Benedict (1993), Comunidades Imaginadas: Reflexiones sobre el Origen y Difusión del Nacionalismo. Ciudad de México: FCE.

Blanchot, Maurice (1983), La communauté inavouable. Paris: Eds. de Minuit.

Bell, Daniel (2016), “Communitarianism”, The Stanford Encyclopedia of Philosophy, Edward N. Zalta (ed.), Recuperado de: https://plato.stanford.edu/archives/sum 2016/entries/communitarianism/

Donaldson, Sue y Will Kymlicka (2011), Zoopolis: A Political Theory of Animal Rights. Oxford: Oxford University Press. 
Esposito, Roberto (2003), Communitas. Origen y destino de la comunidad. Buenos Aires: Amorrortu.

(2005), Immunitas. Protección y negación de la vida. Buenos Aires:

Amorrortu.

(2006), Bíos. Biopolítica y filosofía. Buenos Aires: Amorrortu.

(2009a), Tercera Persona. Política de la vida y filosofía de lo impersonal.

Buenos Aires: Amorrortu.

(2009b), Comunidad, inmunidad y biopolítica. Madrid: Herder.

(2012), “Community, Immunity, Biopolitics", Política Común, Vol. 3

Recuperado de: https://quod.lib.umich.edu/p/pc/12322227.0003.001?view=te $\mathrm{xt}$;rgn=main

(2015), Persons and Things. Cambridge, UK: Polity Press.

Etzioni, Amitai (1995), New Communitarian Thinking. Charlottesville: University of Virginia Press.

Galston, William A. (1993), "The Promise of Communitarianism," National Civic Review, Volume 82, Issue 3, Summer: 1993: 217-220.

Hardt, Michael y Antonio Negri (2005), Multitud. Barcelona: Random House Mondadori.

(2011), Commonwealth. El proyecto de una revolución del común. Madrid: Akal. (2019), Asamblea. Madrid: Akal.

Kymlicka, Will (2018), "Human Rights Without Human Supremacism”, Canadian Journal of Philosophy, Volume 48 (6): 763-792.

Laval Christian y Pierre Dardot (2015), Común. Ensayo sobre la revolución en el siglo xxi. Barcelona: Gedisa.

MacIntyre, Alasdair (1984), After Virtue. Notre Dame: University of Notre Dame Press, $2^{\text {nd }}$ edition.

Maritain, Jacques (1961), Los derechos del hombre. Buenos Aires: Dédalo.

Meijer, Eva (2019), When Animals Speak: Toward an Interspecies Democracy. New York: New York University Press.

Nancy, Jean-Luc ([1983] 1991), The Inoperative Community. Minneapolis: University of Minnesota Press.

(1999), La communauté désoeuvrée, Nouvelle édition revue et augmentée. Paris: Christian Bourgois.

Planinc, Emma (2014), "Democracy, Despots and Wolves: On the Dangers of Zoopolis's Animal Citizen”, Canadian Journal of Political Science/Revue canadienne de science politique 47 (1): 1-21.

Rossello, Diego (2017), ““To be Human, Nonetheless, Remains a Decision': Humanism as Decisionism in Critical Political Theory", Contemporary Political Theory 16: 439-458. 
Taylor, Charles (1989), Sources of the Self: The Making of the Modern Identity. Cambridge: Cambridge University Press.

Saidel, Matías (2013), "Más allá de la persona: lo impersonal en el pensamiento de Roberto Esposito y Giorgio Agamben", Eikasia: Revista de Filosofia; pp. 159176.

Sandel, Michael J. (1982), Liberalism and the Limits of Justice. Cambridge: Cambridge University Press.

Tönnies, Ferdinand (2001), Community and Civil Society. Cambridge: Cambridge University Press. 